\title{
A EXPERIÊNCIA VIVIDA PELAS FAMÍLIAS DE CRIANÇAS HOSPITALIZADAS EM UMA UNIDADE DE TERAPIA INTENSIVA NEONATAL ${ }^{1}$ THE EXPERIENCE LIVED BY RELATIVES OF CHILDREN INTERNED IN THE NEONATAL INTENSIVE CARE UNITS \\ UNA EXPERIENCIA POR LOS FAMILIARES DE LOS NIÑOS HOSPITALIZADOS EN UNA UNIDAD DE CUIDADOS INTENSIVOS NEONATAL
}

\author{
Maria de Lourdes Centaㄹ, Elaine Cristhine Moreira ${ }^{3}$, Magda Nanuck de Godoy Holffling Ribas Pinto ${ }^{4}$
}

\begin{abstract}
${ }^{1}$ Trabalho desenvolvido junto ao Grupo de Estudos Família, Saúde e Desenvolvimento - GEFASED da Universidade Federal do Paraná (UFPR) com Apoio do CNPq e Fundação Araucária.

${ }^{2}$ Doutora em Filosofia em Enfermagem. Professora da Universidade Federal do Paraná. Coordenadora do Grupo de Estudos Família, Saúde e Desenvolvimento - GEFASED.

${ }^{3}$ Enfermeira. Ex-bolsista Iniciação Científica/CNPq. Membro do Grupo de Estudos Família, Saúde e Desenvolvimento - GEFASED.

${ }^{4}$ Professora do Departamento de Enfermagem da Universidade Federal do Paraná.
\end{abstract}

PALAVRAS-CHAVE:

Família. Unidades de terapia intensiva neonatal.

Cuidados de enfermagem.
RESUMO: O objetivo deste estudo foi identificar a experiência vivida pelos familiares de crianças internadas em Unidade de Terapia Intensiva Neonatal num hospital de Curitiba. Os dados foram obtidos por meio de entrevista semi-estruturada; a amostra foi composta por 18 familiares de crianças internadas em UTIN durante os meses de junho e julho de 2003. Trata-se de estudo exploratório-descritivo. Após análise e discussão dos dados, surgiu como categoria central "vivenciando a internação do recém-nascido em UTI neonatal", a qual originou as seguintes categorias: Definição da UTI Neonatal; Motivos de internação do recém-nascido; Perspectiva de informação; Significado da experiência vivida; Sentimentos gerados; Reação dos familiares; Avaliação do cuidado; Participação dos familiares no cuidado; Avaliação da assistência recebida; Envolvimento no cuidado. Em "vivenciando a internação do recém-nascido em UTIN" pelos familiares, conclui-se que apesar do atendimento prestado pela equipe multiprofissional, eles sentem necessidade de mais informações, orientações, aconselhamento e apoio.

\section{KEYWORDS:}

Family.

Intensive care unit neonatal. Nursing care.
ABSTRACT:This study aimed to identify the experience lived by relatives of children admitted in the Neonatal Intensive Care Unit (NICU) of a hospital in Curitiba city. The data have been obtained through a half-structured interview with a sample compounded at 18 relatives of children admitted in NICU during the months of June and July in 2003. It's an exploratory descriptive study. The analysis and discussion of the data determined a central category, "experiencing the admission of the newborn in neonatal intensive care UNIT" that originated the following categories: definition of Neonatal Intensive Care Unit; reasons for the admission of the newborn; perspective of information; significance of the experience; generated feelings; relatives reaction; care assessment; relatives participation in care; received assistance assessment and care involvement. In experiencing the admission of the newborn in neonatal intensive care UNIT by relatives, we concluded that despite the attention provided by the professional staff, they feel the necessity of more information, guidance, advisement and support.
PALABRAS CLAVE: Familia. Unidad de terapia intensiva neonatal. Cuidados de enfermería.
RESUMEN: El objetivo de este estudio fue identificar la experiencia vivida por los familiares de los niños internados en la Unidad de Terapia Intensiva Neonatal (UTIN) de un hospital en Curitiba. Los datos fueron obtenidos a travéz de la entrevista semi-estructurada. La muestra estuvo compuesta por 18 familiares de niños internados en la UTIN durante los meses de junio y julio del 2003. Se trata de un estudio exploratório-descriptivo. Después del análisis y la discusión de datos surgió como categoría central "vivenciando el internamiento del recién nacido en la UTI neonatal", originando las siguientes categorías: definición de la UTI Neonatal; razones de internación del recién nacido; perspectiva de información; significado de la experiencia vivida; sentimientos generados; reacción de los familiares; evaluación del cuidado; participación de los familiares en el cuidado; evaluación de la asistencia recibida y su envolvimento en el cuidado. En "vivenciando la internación del recién nacido en la UTI Neonatal" por los familiares, concluimos que, no obstante la atención prestada por el equipo multiprofesional, ellos sienten la necesidad de mayores informaciones, orientaciones, consejos y apoyo.
Endereço:

Maria de Lourdes Centa

Rua Pará, 1235.

80619-020 -Água Verde, Curitiba - PR

E-mail-mcenta@brturbo.com.br
Artigo original: Pesquisa

Recebido em: 15 de fevereiro de 2004

Aprovação final: 28 de junho de 2004 


\section{INTRODUÇÃO}

Para que o profissional enfermeiro compreenda a experiência de se ter um filho internado em Unidade de Terapia Intensiva Neonatal (UTIN) é necessário que sinta empatia e desejo de cuidar. O nascimento é um momento único, quando, em geral, sonhos, expectativas e objetivos de vida de um casal estão validando-se, e eles estão estruturando a própria família. O filho representa a continuidade da existência da família e é esperado com muito anseio e amor, pois é objeto de sonhos e esperança não somente dos pais, mas de todos os familiares.

Durante a gravidez, os pais sonharam ter um filho sadio, que pudesse ser levado para casa após o nascimento, onde seria criado, amado e amparado. Quando essa criança nasce com algum problema de saúde e necessita ser internado em UTIN, os seus pais sofrem, muitas vezes chegando à crise. Isso se deve ao desejo de ter um filho sadio, ao desconhecimento da patologia da criança e do que seja uma UTIN, à falta de apoio e cuidado da equipe em relação à família, medo da morte, entre outros.

Apesar dos recém-nascidos ( $\mathrm{RNs}$ ) doentes estarem sobrevivendo com mais facilidade devido à alta tecnologia e novos conhecimentos, sua internação em Unidade de Terapia Intensiva (UTI) poderá resultar em transtornos para as famílias, pois elas poderão ter dúvidas sobre a intervenção utilizada, além do desgaste emocional de possuir uma criança com problemas graves.

Observa-se, portanto, a importância dos cuidados desenvolvidos em UTIN, quer em relação à criança, quer envolvendo a família e os próprios profissionais que ali atuam. Essa preocupação levou o Ministério da Saúde a instituir normas para a realização de uma assistência mais humanizada ao recém-nascido (RN) de baixo peso ${ }^{1}$.

Nelas está escrito que o distanciamento dos pais pode aumentar o nível de estresse do bebê, juntamente com o cortisol, o que pode danificar o metabolismo, a imunidade e o próprio cérebro do bebê. Se a criança internada em UTIN precisa dos pais, estes precisam ser cuidados para enfrentar a experiência de ter um filho internado nessa unidade, pois além de todos os fatores que interferem em seu equilíbrio emocional, causado pela doença do filho, ainda existe a falta de conhecimento relacionado a UTIN e aos cuidados ali prestados. O assistir/cuidar dessas crianças requer ações que envolvam a criança, a família e os profissionais ${ }^{1}$.
Sabe-se, entretanto, que no sistema de saúde vigente, a produtividade supera o sentimento humanizado, o que acaba por tornar as restritas e superficiais. Em uma UTI as ações desenvolvidas são de alta complexidade e tecnologia, visando manter a vida de crianças desejadas, esperadas e amadas pelas suas famílias. Portanto, atuar em UTIN requer não só competência e conhecimento, mas principalmente ética, dedicação, amor. As ações ali desenvolvidas devem envolver a família, fazendo com que ela participe do cuidado, diminuindo com isso seu estresse, medo, ansiedade. Isso será possível somente quando se os profissionais estiverem preparados e conscientizados de que cuidar do $\mathrm{RN}$ envolve vários elementos, dentre eles a família.

\section{OBJETIVO}

Conhecer a experiência vivida pelos familiares de crianças internadas em UTIN tendo como finalidade obter subsídios para a melhora da assistência prestada ao paciente e sua família.

\section{REVISÃO DE LITERATURA}

O nascimento é um rito de passagem, porque é caracterizado como um processo de grandes mudanças físicas, simbólicas e sociais que envolvem todas as pessoas da família e da sua rede de relações dos pais da criança. Esse processo relaciona-se com saúde e doença, por isso exige o cuidado de profissionais que levem em conta a herança cultural das famílias, pois só assim a criança poderá adquirir qualidade de vida ${ }^{2}$.

A gestação é considerada um acontecimento saudável e normal na vida dos casais, porém é esperada com muitas expectativas e anseios, gerando uma gama de sentimentos positivos e negativos. Os pais tentam adaptar-se para receber o filho e temem a possibilidade de um parto prematuro ou presença de má-formação. Quando isso ocorre, é um acontecimento inesperado, que causa descontinuidade na idealização do nascimento. Os pais vêem-se impossibilitados de sair do hospital com o bebê nos braços, portanto, vem o medo da morte, de que o bebê não consiga ganhar peso, da suscetibilidade às infecções e complicações neurológicas ${ }^{3}$.

Quando o RN é internado em UTI, além dos problemas já citados, os pais enfrentam o medo da doença e do desconhecido; sentimentos de culpa e insegurança; ausência de controle sobre o ambiente hospitalar; mudança na rotina de vida; insegurança 
quanto ao comportamento do filho; desconhecimento de procedimentos ligados à sua recuperação; problemas financeiros, sociais e afetivos vinculados à doença e à hospitalização da criança; padrões comportamentais diferentes dos habituais ${ }^{3}$.

É importante, portanto, que toda equipe de profissionais que atuam em UTIN esteja apta para amenizar o trauma familiar, causado pela internação da criança, por meio de uma assistência humanizada prestada não só à criança, mas também à sua família. A equipe de enfermagem deve agir de forma integral, tentando interagir com os familiares, atendendo necessidades, apoiando, ensinando e incentivando a participação destes no cuidado. Os profissionais devem ter uma visão holística da criança e de sua família, desconsiderando a visão exclusivamente biomédica, que é centralizada na patologia ${ }^{4}$.

Para se ter uma visão holística do paciente, é necessário envolver a família no cuidado. A enfermagem deve ter competência para avaliar a intensidade do problema que os familiares estão enfrentando e como esse problema interfere no cotidiano deles, para poder planejar e implementar ações eficientes e com resolutividade, procurando tornar o tempo de internamento o mais harmônico e saudável possível.

Compreender a família não é um processo simples, pois cada uma é singular e experiencia de forma particular e exclusiva a internação do RN em UTIN. Durante esse processo, as famílias agem e reagem influenciadas pela herança cultural, com base na interpretação que faz do vivido. Para assistir tais famílias e cuidar delas, o profissional enfermeiro deve procurar conhecê-las e compreender reações, sentimentos, signos, significados, hábitos, costumes e valores. Para isso, faz-se necessário interagir, apoiar e orientar, amenizando a dor. Nesse processo é importante a comunicação estabelecida entre o profissional e a família, pois o efeito das mensagens transmitidas é determinante para a tomada de decisões, da postura e de atitudes relacionadas ao cuidado integral ofertado ${ }^{5}$.

Muitas vezes a assistência padrão prestada à criança e familiares não corresponde às necessidades sentidas pelas famílias. Cabe ao profissional conhecer tais necessidades e tentar supri-las. Sabe-se que a equipe de profissionais que atua em UTIN muitas vezes está mais preocupada em salvar vidas do que assistir e cuidar das famílias, mas ela não deve se esquecer de que a ação dos familiares é fundamental na recuperação do paciente ${ }^{5}$.

A família tem direito de participar da assistência da criança, o que está estabelecido no Estatuto da Criança e do Adolescente (ECA). Em Direitos Fundamentais, Capítulo I, Artigo 10, esse estatuto refere que os hospitais são obrigados a prestar orientação aos pais do RN, e no Artigo 12, que é preciso criar condições para que um dos pais ou responsáveis pela internação da criança permaneçam junto a ela durante a internação ${ }^{6}$. Para que isso ocorra, as instituições de saúde e seus profissionais devem conscientizar-se da importância da participação dos familiares no cuidado, e dar condições para que eles envolvam-se nesse processo, exercendo não somente funções como familiares, mas direitos de cidadãos. Nessa circunstância, cabe à enfermagem cuidar não só da criança, mas assistir também a família.

\section{METODOLOGIA}

Estudos exploratório-descritivos baseiam-se na coleta de descrições detalhadas das variáveis do fenômeno retratado. Os dados justificam e avaliam a realidade ou servem para sugerir e implementar soluções no sistema de saúde?

Optou-se pela pesquisa qualitativa, cuja finalidade é estudar a experiência humana, importante para a ciência da Enfermagem porque permite analisar o processo de saúde/doença das pessoas ${ }^{8}$.

A análise dos dados obtidos baseou-se no método de Bardin, o qual permite analisar o conteúdo, enfocando seus principais aspectos. Após a codificação das falas dos participantes do estudo, as mesmas formaram categorias e subcategorias. Para preservar o anonimato dos participantes, suas falas foram identificadas por meio de sinais da escrita musical'.

Esse estudo teve como amostra 18 familiares de crianças internadas em UTI e foi realizado nos meses de junho e julho de 2003, em um Hospital Universitário de Curitiba.

Para a realização desse estudo foi respeitada a Resolução n. ${ }^{\circ}$ 196/96 Diretrizes e Normas Regulamentadoras de Pesquisa em Seres Humanos, no que se refere ao esclarecimento dos objetivos do estudo, sigilo, anonimato, desejo de participar, possibilidade de desistência e utilização dos dados. Foi solicitado aos participantes Consentimento Livre e Esclarecido ${ }^{10}$.

O projeto dessa pesquisa foi apreciado pelo Comitê de Ética e Pesquisa em Seres Humanos do Hospital das Clínicas, recebendo aprovação.

Os dados foram coletados mediante entrevista semi-estruturada, com perguntas abertas. Para manter 
a fidedignidade dos dados, foi utilizado gravador, após consentimento dos sujeitos da amostra, e caderno de campo, onde eram anotadas as ocorrências que o entrevistador considerava de relevância para o estudo.

\section{DISCUSSÃO E ANÁLISE DOS DADOS}

Após a obtenção dos dados, os mesmos foram lidos, relidos e, posteriormente, agrupados, donde obtiveram-se os resultados apresentados a seguir.

Em relação à identificação dos sujeitos, 22\%(4) tiveram seus filhos internados em UTIN pelo período de 1 semana, $45 \%$ (8), por $2-3$ semanas e $33 \%$ (6) por mais de 4 semanas. Isso demonstrou que as crianças permanecem internadas em UTIN por grande período de tempo.

Quanto à escolaridade, 52\% (9) dos sujeitos possuíam o Ensino Fundamental, 36\% (6), Ensino Médio e 12\% (2), Ensino Superior.

Em relação à permanência de familiares na UTIN para participar da assistência e cuidar do RN, verificou-se que as mães são as que mais participam, $83 \%$ (15), sendo seguidas pelos pais, $11 \%$ (2) e avós, $6 \%$ (1). Talvez isso se deva à rotina específica desse serviço de saúde, que restringe o acesso dos familiares ao local, permitindo a entrada somente de pais e avós. Os pais podem permanecer com as crianças por período integral e aos avós é permitida visita uma vez por semana. Para outros familiares é negada a visita.

A maioria dos casais, 44\% (8), possui 2 filhos, incluindo-se o RN, $22 \%$ (4) estão sendo pais pela primeira vez, e 34\% (6) possuem mais de 3 filhos.

Após análise e discussão dos dados obtidos nas entrevistas, construiu-se a categoria central deste estudo: vivenciando a internação do RN em UTIN, a qual originou as seguintes categorias: definição da UTIN; motivos da internação; informações recebidas; reação dos familiares; significado de ter um filho internado na UTIN; sentimentos gerados; avaliação do cuidado; participação dos familiares no cuidado; envolvimento no cuidado; avaliação da assistência recebida e subcategorias.

$\mathrm{Na}$ categoria definição da UTI Neonatal, os sujeitos definiram essa unidade de serviço como instrumento para se evitar a morte, local onde há assistência especializada e que recebe RNs em estado crítico de saúde, na qual existem recursos adequados e pessoal especializado para atender as necessidades da criança.

Eu acho que é pra [...] não deixar o bebê morrer (Colcheia).
É um lugar especial, onde as crianças que necessitam de tratamento especial ficam, precisam de cuidados mais intensos (Semicolcheia).

Eu acho que é um lugar assim [...] que eles cuidam da pessoa que está mal, bem mal de saúde, pessoa que está [...] só usando os aparelhos pra ter mais vida(Minima).

Existem alguns familiares que não conhecem o ambiente de uma UTIN, seus objetivos e as atividades ali desenvolvidas, os quais tiveram dificuldade para expressar-se quando foram argüidos sobre o assunto.

Ah, agora você me pegou, é minha primeira experiência porque eu nunca tive um bebê na UTI, então para mim é a primeira vez que eu entro em uma UTI! (Pausa).

Em motivos da internação, os participantes relatam que os RNs são internados em UTIN quando apresentam estado crítico de saúde, má-formação, prematuridade, necessidade de reanimação cardiopulmonar, ou seja, quando apresentam risco de vida.

Quando ela tem risco de vida! A minha tinha risco de vida, ela já nasceu com o coraçãozinho quase parando. E dai ela estava com risco de vida. Quando é prematuro sempre tem que ir para UTI (Pausa).

A má formação, como diz. [...] a não houve formação inteira dela, dentro daquele período dentro do útero da mãe (Sustenido).

Ah, não sei. Eu acho que prematuro, bebê que apresenta algum risco, alguma coisa, não sei, eu nem conbecia uma UTI Neonatal, nem sabia que nasciam bebês tão pequenos como tem ali! (Harmonia).

Nas informações recebidas, os familiares referem desejo de serem informados sobre o que está acontecendo com seu filho, orientados a respeito da internação e dos cuidados prestados ao $\mathrm{RN}$, manifestando o desejo de estarem presentes e acompanharem a evolução do estado de saúde da criança. Eles relatam como se processam as informações recebidas e falam das alterações em seu estado emocional como obstáculo para o entendimento das orientações recebidas.

Essa categoria deu origem às seguintes subcategorias: recebendo informações, fontes de informações, tirando dúvidas, querendo informações.

Em recebendo informações, os pais relataram que recebem informações, mas que querem saber o que está acontecendo, pois muitas vezes, devido à tensão, estressee ao cansaço, eles não entendem o que foi explicado/informado.

Porque a gente está naquela tensão, estresse, cansaço, de vez. em quando a gente entende, às vezes não (Harmonia). 
Me explicou, mas en estou tão [...] que en já nem sei mais! (Pauta).

Com um prematuro é assim, cada dia é um dia [...] então todo dia eu venho, eu quero saber o que está acontecendo naquele dia (Ligadura).

Em fontes de informação, os profissionais mais citados foram pediatra, enfermeiro e, em menor número, obstetra; algumas famílias citaram toda a equipe, e houve quem não soubesse informar.

A Enfermeira que me explicon o que foi feito(Fusa).

O médico que está cuidando da minha esposa, ele nos deu uma certa orientação, mas muito leve (Sustenido).

Todo mundo, toda a equipe né? Tanto médico, as auxiliares de enfermagem, as enfermeiras, todo mundo (Escala).

$\mathrm{Na}$ subcategoria tirando dúvidas, percebeu-se que os participantes consideraram o médico a fonte mais confiável de informações, e que a Enfermagem, embora possua conhecimento do caso, muitas vezes não informa, encaminhando a família para receber informações do médico. Observa-se, também, que a mãe é fonte importante de orientação, o que se deve ao nível de confiança na rede de relações familiares.

Quando as Enfermeiras não sabem, não podem informar, elas mandam conversar com a Doutora também (Bemol).

Ali a gente vê tudo, ai qualquer dúvida pergunta para Enfermeira [...] e qualquer dúvida maior com o médico (Clave).

Tem a pediatra, e as enfermeiras que ficam com ela, cada ver que eu chego, eu pergunto dai elas falam se está tudo bem, é assim [...] Eu entendo, dai o que eu não entendo eu chego em casa e pergunto para a minha mãe, e ela me explica tudo de novo (Semibreve).

Em querendo mais informações, mesmo observando que a equipe está empenhada em desenvolver seu trabalho, os familiares demonstram o desejo de serem informados sobre o que está acontecendo com o RN. Quando as informações não são dadas espontaneamente pela equipe profissional, a família aborda os profissionais para tirar dúvidas e saber o que está acontecendo.

Dai en que pergunto, porque acho que fica muito corrido para ela (Colcheia).

Eu sempre pergunto, porque nunca vem de livre $e$ espontânea vontade da parte de ninguém(Sincope).

$\mathrm{Na}$ categoria reação dos familiares, os pais relataram sentimentos positivos e negativos causados pela internação do RN em UTIN, demonstrando o envolvimento de toda a família. Houve referência também a incompreensão, apoio e cobrança da família, que depende da assistência/cuidado prestado pela instituição e busca apoio, consolo e esperança na fé em Deus.

A minha familia me ajudou bastante! Foi um momento que estiveram do meu lado, e estão fazendo o possível! Eles fizeram o que melhor podiam!'Eles fizeram! (Apogiatura).

É a gente fica abalado né? E quando chego em casa os parentes ficam perguntando: Cadê teu filho? Por que não vem embora? É aquela cobrança. Dai quando a gente fala de UTI eles acham que está mal... Ai! Meu Deus! É fraquinho! Não vai resistir! (Escala).

Nossa, minha mãe, meus irmãos, ficaram todos nervosos! Fizeram bastante oração pra ela! Todo mundo pedindo oração, e graças a Deus ela está aí! (Clave).

Em significado de ter um filho internado na UTIN, a família relata que o RN é esperado como uma criança saudável, não suscetível a doenças. Então nasce uma criança com problemas que necessita de internação. Ocorre um fato inesperado, é uma experiência única, quando a conscientização dos riscos gera sentimentos de insegurança, medo, ansiedade, dor e tristeza. Sendo assim, muitas vezes os familiares não gostam de falar sobre o assunto.

Nunca pensei que ia passar por isso, pensava que ia ser tudo normal, porque nenhum pai imagina uma coisa dessas, então, todo pai imagina ir lá pegar o filho no colo e abraçar a mãe! É muito triste, você não sabe o que vai acontecer [...] (Sustenido).

Falar do assunto para mim é [...] me emociona porque [...] (choro) porque não é fácil. Na verdade eu não gosto nem de falar, por tudo o que eu passei, então, não foi fácil pra mim (Semifusa).

Foi muita dificuldade, muita dor, então no comecinho eu não tive coragem de ver meu filho, eu tinha medo (Apojatura).

Tem um determinado momento que você não pode pegar, você só toca, você não pega no colo. Eu ficava ansiosa, e com medo [...] então é triste. É bom saber que está sendo bem tratado, mas eu queria ele em casa! (Escala).

$\mathrm{Na}$ categoria sentimentos gerados, os familiares referem segurança no atendimento, fé, medo, desespero, impotência, tristeza, nervosismo, como se tivessem arrancando um pedaço deles e as mães não se sentem completas.

Eu gostaria de passar mais tempo, mas eu fico ner- 
vosa dentro da sala lá da UTI, de ver ela naquele estado, eu me sinto mal sabe? Me sinto mais deprimida! (Seminima).

Um momento bem dificil foi quando eu tive que deixar o hospital, né? Nossa, foi assim como se estivessem arrancado um pedaço de mim, foi horrivel! (Ligadura).

Ah, eu me senti segura que eles estavam cuidando (Minima).

Olha, no começo, eu fiquei com medo! Não sei se é porque eu passei por tanta dificuldade na minha gravidez, desde o início. Foi muito difícil, no comecinho eu não tive coragem de ver meu filho. Tanto é que quem viu primeiro foi o pai dele. Foi ele que me deu força! Porque quando eu sai da ecografia, antes de ganhar, a médica que fez a ecografia falou que ele estava cheio de lesões, cheio de não sei o que, quer dizer a médica me deixou com medo, entendeu? Eu já estava num momento difícil e ela me passou mais medo ainda, então quando eu ganhei, eu fiquei horrorizada, fiquei com medo, fiquei com trauma, mas depois eu tive coragem, é o meu filho né? E [...] fui ver o meu filho [...] mas é difícil (Apogiatura).

Eu me sinto insegura, com medo pois ela, só está viva porque Deus está olhando e os médicos estão cuidando! (Pausa).

É triste! É triste! Porque a gente, assim eu não me sinto mãe assim completa [...] porque eu primeiro que não senti, não vi saindo dentro de mim, porque eu estava quase morrendo, então tiraram ela. Eu não tive aquele [...] sentimento que todo mundo fala: Ai como é bom, né? Você vê ele saindo, estar perto de você, não tive isso e aqui a gente não pode [...] fazer nada [...] (Escala).

Quanto à avaliação do cuidado ao RN, os familiares avaliam o atendimento como de qualidade, comparando com outras instituições e até mesmo com o próprio cuidado familiar. Eles enfatizam o cuidado humanizado e a confiança nos profissionais. Apesar de estarem experienciando um momento difícil, a maioria consegue avaliar a internação como algo positivo para o estado de saúde de suas crianças. Outros acham que o cuidado poderia ser melhorado.

Ah, eles estão cuidando muito bem! Nossa em tudo! Não tem o que reclamar não, muito bom mesmo, como se fossem a mãe dela, porque eles cuidam mais do que a gente, eles estão 24 horas com eles (Clave).

Muito melhor do que o hospital que tem lá em $C$. (Semibreve).

Está bom, mas acho que podia melhorar! Os cuidados que eles fazem assim em aspirar o bebê, sabe [...] o bebê prematuro, acho que deveria ter um certo cuidado, existe umas enfermeiras que não têm cuidado, quase arrancam o nariz do bebê, para fazer isso, então, acho que poderia me- lhorar! A chefe de enfermagem podia conversar com as enfermeiras, explicar para elas que por ser prematuro tem que segurar com delicadeza, tem que fazer com mais cuidado a aspiração, tem umas enfermeiras que quase matam, quase quebram o pescoço do bebê acho que poderia melhorar um pouquinho! (Fusa).

Em participação dos familiares no cuidado, eles expressam a vontade de permanecer 24 horas na unidade, o desejo de cuidar e as dificuldades enfrentadas, além da liberdade que a instituição oferece para isso. Outros referem que não sabiam o que fazer para estarem mais ligados às suas crianças. Eles referem, também, o uso de aparelhos, peso, tamanho do RN e o medo de transmitir doenças como obstáculos para a realização do cuidado.

Queria ficar com ela 24 horas, poder pegar no colo, dar de mamar, tudo sabe? Mas assim, eu não posso, porque ela está nos aparelhos! (Semibreve).

Ele é muito pequenininho, então tenho que saber tudo direitinho o que faz, e isso é só com eles! (Ligadura).

No começo eu queria pegar ele, cuidar...mas não tinha jeito. Agora eu já estou pegando ele! Ele já está no bercinho, não está mais na incubadora, então eu faço com ele o que eu quero, as enfermeiras sempre estão por ali, mas eu já estou trocando, estou amamentando, estou fazendo tudo né? Agora que estou me sentindo mãe né? (Escala).

Para cuidar dela aqui eu acho que eu não tenho muito jeito não, porque assim cuidar que nem eles cuidam eu não sei, também eu acho que eles sabem cuidar muito bem. Eu só venho ficar com ela, olhar ela, passar a mão nela, só isso! Dai quando ela estiver boa, eu levo ela embora e cuido da minha forma (Semibreve).

O caso dela é muito delicado então não tem como a gente ficar muito próximo também, eu poderia estar resfriado e podia transferir para criança isso seria fatal né? Ainda mais o caso dela! (Bemol).

Em envolvimento no cuidado, os familiares expressam insegurança, o não saber cuidar, o uso da incubadora como obstáculo à realização do cuidado, o medo da incubadora, a falta de experiência, a delicadeza do cuidado, a necessidade de mais orientações, de sentirem medo, insegurança e o incentivo recebido para executarem o cuidado. Demonstram que estão comprometidos com o cuidado, mas se sentem incapazes de realizá-lo devido à situação em que se encontra o RN e o despreparo deles para participarem dos procedimentos do cuidar.

Ah, eu acho que já cuido porque eles incentivam dar mamá no peito, trocar, então o maiorzinho já estou trocan-

Texto Contexto Enferm 2004 Jul-Set; 13(3):444-51. 
do! Só o pequenininho que eu ainda tenho insegurança [...] de trocar porque é muito pequenininho. Mas está ali e está sendo cuidado! O maiorzinho eu pego no colo, fica comigo um pouco, fico dando carinho, só o pequenininho [...] que eu não consigo [...] então eu passo a mão, mas é muito pequenininho, eu não posso pegar ainda, não posso [...] Até trocar a fralda eles já me incentivaram, mas eu tenho medo, o problema é comigo, né? Eu tenho muita insegurança, mas eles me incentivam bastante! (Semicolcheia).

Para cuidar dela aqui eu acho que eu não tenho muita forma não, porque assim, cuidar que nem eles cuidam eu não sei (Semibreve).

Ali como está na incubadora? Ab, eu acho que não! Eu acho que só depois que sair dali é que a gente vai ajudar a cuidar, a trocar, segurar, amamentar! (Pausa).

Com relação a cuidar dela de alguma maneira é meio complicado porque a assistência é muito delicada, a gente não tem experiência. Não sei se os pais tivessem algum curso, alguma coisa, uma orientação antes, até eu queria ajudar em alguma coisa, mas em caso contrário fica difícil. Eu não faço porque a maneira que pega nela ou mexe com ela é complicada, entende? (Bemol).

Avaliação da assistência recebida pela família originou três subcategorias: Recebem assistência, Não recebem assistência, Prestador de assistência.

Em recebem assistência, os familiares referem que a equipe de profissionais assiste/cuida das famílias através do modo como ela se comunica.

A começar pela entrevista [...] é algo que ajuda bastante a gente a se comunicar, a demonstrar a situação (Sustenido).

Acho que todos se preocupam porque do jeito que eles falam com a gente (Semibreve).

Em não recebem assistência, a família relata que os profissionais se preocupam em prestar cuidados aos RNs mas não se preocupam com ela própria.

Comigo acho que não se preocupam, [...] eu acho que eles têm que se preocupar com os bebezinhos, porque as mães tão bem! (Fusa).

Mas ninguém até agora, ninguém chegou em mim perguntando como que eu me sinto, entendeu? Comigo não! É [...] me confortando assim do hospital não! Ninguém! Nem da UTI. Eles não se preocupam com o estado de espirito da mãe, com o desespero da mãe, eles não. Os médicos são até meio frios, eles são frios e realistas demais, isso às vezes machuca muito a mãe. Eles não dão assistência nenbuma à mãe, assim no sentido do espirito de acalmar o espirito da mãe eles não se preocupam com isso! (Ligadura).

Aqui quem está sendo bem assistido é o meu filho.
Eu também, no meu parto, fui muito bem assistida, se preocuparam muito comigo sabe? Me trataram com carinho,.... sempre me cuidando. Mas depois que você ganha alta é do teu filho que eles cuidam então, acabou aquela parte de cuidar de você, entendeu? (Ligadura).

Eles dão assistência ao teu filho que está na UTI e está precisando! Ninguém se preocupa se você anda triste, deprimida ou até mesmo desesperada. Ninguém, se preocupa com essa parte! (Apogiatura).

Como prestador de assistência, eles citam os médicos e a assistente social e, com freqüência menor a enfermeira, embora ela esteja presente na unidade, por mais tempo que os profissionais citados.

Os médicos, eles cuidam da gente (Minima).

A Assistente Social tenta ajudar, né? (Bemol).

Bom, eu acho que as próprias enfermeiras que estão ali rodeando a gente! (Clave).

\section{CONSIDERAÇÕES FINAIS}

A experiência de ter um filho internado em uma UTIN é marcada por sentimentos de medo, insegurança e tensão, o que pode abalar a estrutura familiar como unidade de cuidado. Nesse processo é importante que os profissionais de saúde e mais especificamente a equipe de enfermagem, prestem acompanhamento integral às famílias. O enfermeiro deve promover a aproximação e o envolvimento dos familiares com o cuidado prestado à criança. Para que isso ocorra, os profissionais de enfermagem que atuam em UTIN devem oferecer apoio, informando e orientando sobre o estado do $\mathrm{RN}$ e formas de realizar o cuidado. Os enfermeiros não devem preocupar-se somente com o estado de saúde do RN mas também com sua família, procurando minimizar medos, ansiedade, tristeza e dificuldades, pois eles são atores importantes no processo de cura e de desenvolvimento e crescimento do RN. Para isso devem abrir canais de comunicação mais efetivos com os familiares, principalmente nos primeiros dias da internação, informando inclusive protocolos de tratamento e resultados esperados. Isso fará com que os familiares se sintam menos ansiosos e temerários em relação à saúde de seus filhos; proporcionará maior interação entre equipe e família; motivará a participação no cuidado. Enfim, dependendo da atenção e do cuidado recebido pela família do RN internado em UTIN, ela estará mais apta a cuidar do RN, quer no ambiente hospitalar, quer em domicílio. Esse processo está relacionado principalmente ao cuidado de enfermagem, cujas ações 
devem ser planejadas e implementadas com base no cuidado integral do ser humano, envolvendo o $\mathrm{RN}$ e seus familiares. A família que possui um RN em UTIN passa por momentos de angústia, tristeza e medo, fatores estes que exigem da enfermagem a prática do cuidado humanitário, de que as enfermeiras tanto falam, mas que, talvez por herança cultural, muitas vezes deixam em segundo plano, priorizando a técnica e a complexidade do cuidar.

A UTIN é uma unidade de alta complexidade, onde o viver e o morrer estão mais presentes no imaginário das famílias. Sendo assim, os profissionais de enfermagem devem aliar técnica e cuidado humanitário ao conhecimento, oferecendo cuidado integral a todos os seres humanos inseridos nesse contexto.

\section{REFERÊNCIAS}

1 Conselho Nacional de Saúde (BR). Atenção humanizada ao RN de baixo peso: Método Mãe-canguru. Brasília: O Conselho; 2002.

2 Monticelli M. O nascimento como um rito de passagem: abordagem para o cuidado às mulheres e recém-nascidos. São Paulo: Robe editorial; 1997.

3 Maldonado MT. Maternidade e paternidade: situações especiais e de crise na família. Petrópolis: Vozes; 1989.
4 Gonzaga MLC, Arruda EN. O cuidado na hospitalização: uma perspectiva infanto-juvenil. Texto Contexto Enferm 1998 Maio-Ago; 7(2): 195-218.

5 Ribeiro NRR. A família enfrentando a doença grave da criança. In: Elsen I, Marcon SS, Santos MR. O viver em família e sua interface com a saúde e a doença. Maringá: Eduem; 2002.

6 Conselho Nacional de Saúde (BR). Estatuto da Criança e do Adolescente. Brasília: O Conselho; 1991.

7 Lobiondo-Wood G, Haber J. Desenhos não-experimentais. In: Lobiondo-Wood G, Haber J. Pesquisa em enfermagem: métodos, avaliação crítica e utilização. $4^{\mathrm{a}}$ ed. Rio de Janeiro: Guanabara-Koogan; 2001. p. 110-21.

8 Marcus MT, Lieh R. Abordagens de pesquisa qualitativa. In: Lobiondo-Wood G, Haber J. Pesquisa em enfermagem: métodos, avaliação crítica e utilização. $4^{a}$ ed. Rio de Janeiro: Guanabara-Koogan; 2001.p. 122-39.

9 Rodrigues MSP, Leopardi MT. O método de análise de conteúdo: uma versão para enfermeiros. Fortaleza: Fundação Cearense de Pesquisa e Cultura; 1999.

10 Conselho Nacional de Saúde (BR). Resolução n. ${ }^{\circ} 196$ de 10 de outubro. Dispõe sobre as diretrizes e normas regulamentadoras de pesquisa envolvendo seres humanos. Brasilia: O Conselho; 1996. 